University of Nebraska - Lincoln

DigitalCommons@University of Nebraska - Lincoln

Faculty Publications, College of Journalism \& Journalism and Mass Communications, College Mass Communications

September 2005

\title{
Overexposed: Issues of Public Gender Imaging
}

Pamela K. Morris

University of Nebraska-Lincoln, pmorris2@unl.edu

Follow this and additional works at: https://digitalcommons.unl.edu/journalismfacpub

Part of the Journalism Studies Commons

Morris, Pamela K., "Overexposed: Issues of Public Gender Imaging" (2005). Faculty Publications, College of Journalism \& Mass Communications. 1.

https://digitalcommons.unl.edu/journalismfacpub/1

This Article is brought to you for free and open access by the Journalism and Mass Communications, College of at DigitalCommons@University of Nebraska - Lincoln. It has been accepted for inclusion in Faculty Publications, College of Journalism \& Mass Communications by an authorized administrator of DigitalCommons@University of Nebraska Lincoln. 


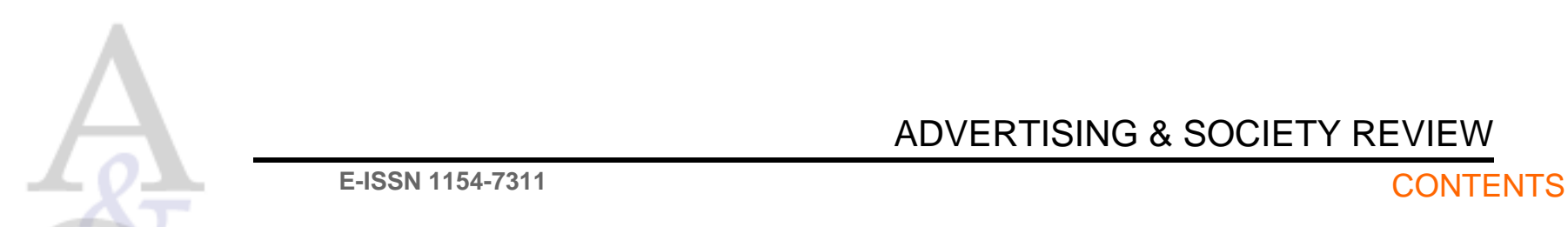

MISSION Overexposed: Issues of Public Gender Imaging

CURRENT ISSUE

EDITORIAL BOARD

CURRICULUM PROJ ECT

SUBMISSION GUIDELINES

ARCHIVES

PROJECT MUSE

SUBSCRIPTIONS

COPYRIGHT

Published by

Advertising

Educational

Foundation
Pamela Morris

\begin{abstract}
:
Make no mistake - it is popularity that makes pop culture important. And it is the powerful visual imagery of advertisements that helps define the largely artificial construction we call gender. Sex-role stereotyping and gender representations are typically studied in content analyses of television and magazine advertisements. Less common are investigations into outdoor advertising, a medium that is ubiquitous and the most democratic-everyone has equal access to visuals. This essay calls attention to and offers insights on advertisements in our outdoor visual space, focusing on gender representations. Capturing and analyzing these ephemeral images can show how they influence how we feel, think, look, and act like a man or a woman through commercialization.
\end{abstract}

Outdoor advertisement is our national landscape-there is no better time capsule, no better record of everyday objects, ideas, actions, and social interest. Bright by day, illuminated at night, brand messages blink, throb, and scream at every opportunity. A concentrated image comes to mind: Times Square, where the "bling" of pretty men and women, words, images, and products for sale never stops and constantly changes. Below, the consuming masses, their senses stimulated, are entertained and informed, but most importantly-they are socialized into a uniform consumer.

We all know that images are powerful. But just what does that mean? Consumer images in public spaces are even more powerful than those found elsewhere. How so? Why? A review of advertisement visuals in a major U.S. metropolis, New York City in this study, at a particular moment offers a peek into the vast reservoir of social values, morals, fashions, and culture of our national civilization. The following visual walk-through tells only a bit of the elaborate story. Important also is talking to the people who created these types of images.

Throughout the world, public space is increasingly commercialized. Any surface that can act as a vehicle for communicating a message is - sides of buildings, water towers, gas pump handles, parking meters, sidewalks, and billboards, to name a few. Outdoor visuals don't discriminate. They are the most democratic of all advertising vehicles. Images of all kinds are available for all to see-young, old, rich, poor, male, and female. At anytime, day and night, you may see them with your grandparents, mom, dad, aunt, uncle, sister, brother, boyfriend, and girlfriend.

By stimulating materialistic drive, they create demand and influence values. Advertisements guide thinking, action, and behavior as people come to accept mainstream ideas through visuals. The most crucial of these is what it means to be a man or a woman. Ideas about how to feel, dress, look, and behave, and how to interact with other men and women is the bedrock of the culture in which we live. Many of these codes of conduct come straight from advertisements. Why not? Our knowledge comes from somewhere. Images help shape our 
expectations and interpretations for what is masculinity and femininity. Through mimicking ideals—like fashions, hairstyles, poses, and attitudes—concepts are codified as culture. The consumed dress, action, and behavior are used as inspiration for future advertisements, reinforcing and creating a circle of culture. Simultaneously, advertisements are both cultural indicators and cultural artifacts, acting as echoes, mirrors, and historic notes.

My adventure began by exploring the outdoor segment of the advertising industry and literature of gender. In order to investigate the creative process first-hand, I met and interviewed several professionals who were responsible for commercial outdoor messages. Meanwhile, armed with my mechanical Pentax Camera, I systematically walked the streets of Manhattan to collect images. The analysis centers on the representation of the human figure in outdoor advertisements.

While this essay is based on an exploratory study, my goals are to understand the importance and current state of outdoor promotional visuals and to focus on images of people. Recording the messages in our common everyday public space can shed light on images that are, at the same time, both ephemeral and important in socialization. The scope is on visuals of people in outdoor advertisements in New York City, a cultural epicenter. Manhattan was chosen because, if not officially, it is perceived to be the leader in business and culture, especially advertising, media, and fashion. Ideas born here spread across the nation and throughout the world.

\section{Gender is a Universal Image}

The body is a universal image and anthropologists suggest it is central for the formation of language, cognitive processes, and structures of culture (D'Andrade, 2001; Lakoff \& Johnson, 1980). Anthropologists have reminded us for years that gender is intertwined in perceptions of social reality and normalized behavior. Cultures have strong notions for how men and women should think and act-standards are not written rules, but are conveyed through socialization based on gender, race, and class (Bordo, 1993). Feminists and critical theorists believe social identities are constructed and co-constructed in discourse (Pillar, 2001).

Advertising is commonly singled out for the role it plays in providing and transmitting standards and ideals. Williams (1980) argues advertising's primary goal is to teach social and personal values, including gender construction (in Pillar, 2001). Specific to gender, although not exclusive to it, advertisements use stereotypes to quickly convey messages and ideas. Feminist scholars have written extensively about advertisers' use of sex-role "stereotypes to instantly and non-verbally communicate with target audiences" (Buttle, 1989, p. 9). Butler (1997) argues that the visual embodiment practices of advertisements are central to construction of identities because the body is "the rhetorical instrument of expression" (p. 152; in Pillar, 2001, p. 171). At issue is the narrow and limiting role women are boxed intosexualized ideals. Images contribute to gender roles that are generally unconscious and subtle but constrain women from opportunities and advancement in the public sphere, including in business and government.

The advertising industry acts as an economic engine, developing commerce for great nations, such as the United States. Stereotypical images have grown alongside. Why and when are gender stereotypes used in visuals? How do professionals understand gender images in relation to society?

\section{Outdoor Grows with Economic Opportunities}

Outdoor advertising can trace its origins back to the earliest civilizations-Egyptian obelisks publicize laws and treaties (OAAA Website, 2003); Babylonia esteemed the value of advertising by hanging signs to identify and draw attention to specific products and services (Tocker, 1969). After invention of the lithographic process in 1796, it took another six decades for Jules Chéret, credited as the father of the modern poster, to complete the first advertising poster by employing words and images in an overall design (WetCanvas Website, 2005). In 1891 the Associated Bill Posters' Association was founded in Chicago and by 1900 a standardized billboard structure encouraged national campaigns, including Coca-Cola, Kellogg's, and Palmolive (OAAA Website, 2003). Cost efficiencies were gained from the large 
market and mass production of billboards.

The medium grew along with the car culture. Billboards are fondly remembered along our nation's roads in the 1940s and 1950s. The primary rectangular format echoed the madly successful movie industry and particularly the new wide CinemaScope screen. ${ }^{1}$ Movies brought fantasy, relaxation, optimism, and an escape from reality to the lives of many who were just recovering from a worldwide economic depression and war. Movies achieved unprecedented attendance in this larger than life, full color, wide screen pop culture. Outdoor billboards could emulate those experiences through their placement, shape, and illumination.

Their sheer size placed the image in sharp contrast with the surrounding rural landscape in a surreal manner. Nocturnal lighting provided prestige and authority to the advertised brand. Meanwhile the automobile had become closely aligned with family values, and it was from the car with the family that you saw the advertisements, creating a comfortable and positive impression for the brand. Later, when the consumer thought of the product, he or she could recall wholesome American values.

After the euphoric bliss, tough times confronted billboards in the 1960s, when advertising dollars followed eyeballs to television. Plus, in 1965, President Johnson confronted the popular roadside visuals by signing into law the Highway Beautification Act that supported the removal of billboards by linking them to federal highway aid. The cleansing of the driver's roadside view may have resulted in the neglect of the billboard, but not in its oblivion. Like a good weed, it flourished under adverse conditions.

Also in the 1960s, Volkswagen Beetle's campaign, "Think Small and Avoid Gas Pains," was one of the first marketing efforts to employ "outdoor" with integrated media, crucial in developing a brand image. During the 1984 Olympics in Los Angeles, Nike advertisements featured Carl Lewis jumping across freeways. Images captured the public's imagination and helped to establish outdoor as an experiential medium (Maskulka, 1999).

New technology in imaging, printing, and materials, provides outdoor advertisers more and varied opportunities. Outdoor expenditures have grown consistently since 1970 (except for 1992) to $\$ 5.2$ billion in 2002 (OAAA Website, 2003). Outdoor is categorized into several basic types: billboards, transit, street furniture, and alternative (for details, see Figure 1).

Figure 1 (PDF)

\section{Big Pictures, Slow Motion}

Using Manhattan as the sampling universe, I observed billboards close up while walking along streets. ${ }^{2}$ The pedestrian's view is a little slower than traveling by car or taxi and a little closer to the ground than a bus rider's view. All advertising messages with images of people that could be seen from this perspective were photographed. Pictures were taken without an agenda in mind; accept that advertisements must include a human figure-photograph, illustration, or shape. And it did not matter if they were male, female, or any other disposition. The goal was to create a snapshot of gender images that were available for all to see.

A total of 134 outdoor visuals with people were collected. My photographs document what I saw. They are not intended to be judged on composition, exposure, or other technical perspectives. Of the outdoor categories, billboards represent the largest, sixty-two percent, while the combination of transit and street furniture makes up the balance (Table 1).

Proportions are roughly the same as in the industry as a whole (the alternative group was not sampled), indicating that the sample is a fair representation of what the industry produces. Although the study is not quantitative, it shows that the industry covers the complete visual spectrum. The tapestry of advertisements is placed for the most effective coverage where we as mobile consumers and potential customers tend to look.

Table 1 (PDF)

A quick overview shows that most advertisements include women, while a statistical analysis 
concurs with this point. Half of the outdoor advertisements show women only, while men only and men and women together equally split the remainder (Table 2). The prominent category is fashion with sixty-two boards (47\%). Women dominate this group with forty boards alone (65\%). Non-fashion boards are equally distributed between genders (Table 3). (My research in general interest magazines shows the opposite to be true, mainly because there are fewer fashion advertisements-and therefore women-in publications such as Time, Newsweek, and People.)

Tables 2 and 3 (PDF)

For purposes of this discussion, I selected twenty-seven images that tell a story about outdoor advertisements, people in these messages, and gender images. Visuals are representative in that any one could encounter images of this type on an average day in Manhattan.

\section{Conversations With Practitioners}

Around the time I took the photographs, I talked with advertising professionals to discuss influences in the creative development of outdoor advertising that produce images of people for all of society to see. ${ }^{3}$ Informants were purposively selected to include members of the advertising industry who were responsible for creative development of advertising campaigns in general and outdoor advertising specifically. In-depth interviews ${ }^{4}$ were conducted with seven creative, production, and sales staff members associated with development and implementation of outdoor advertising. All were senior executives, each with experience of over ten years.

\section{Wished for Realities}

Images are information. Outdoor visuals transform how men and women look, but also how they look at themselves and others. Images provide a framework for perception of stereotypes, individuality, commercialism, and culture.

\section{Outdoor Is Ubiquitous}

Outdoor is employed for the obvious - it is big (or at least can be), it is everywhere, everyone can see it, and it makes for powerful imagery. Times Square, probably the quintessential example of a barrage of outdoor images, is remarkably close to where the first large outdoor poster was created in 1835 for a circus 5 (OAAA Website, 2003). No matter where you point and shoot, images compete for space (Figures $2 \mathrm{a}$ and $2 \mathrm{~b}$ ).
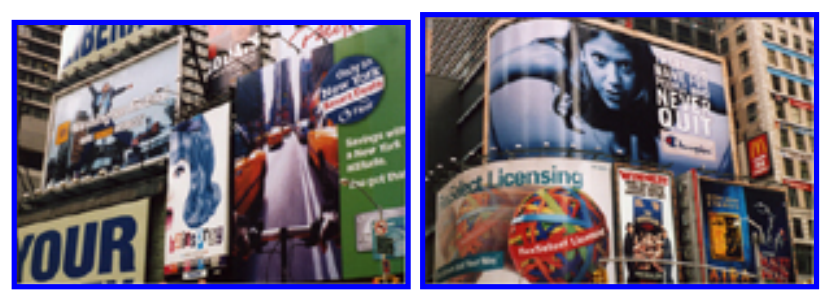

Figures $\mathbf{2 a}$ and $\mathbf{2 b}$. "[Outdoor] is everywhere, for everyone to see...

everyone sees it, from the cab driver and the truck driver to the guy getting a limo ride... you can't help but see a good board. It's everywhere." - Creative Director

Of course, the proliferation of visual messages invading our space is not exclusive to Times Square. People in advertisement images can be seen all over Manhattan. An example is the construction scaffolding shown in Figure 3.

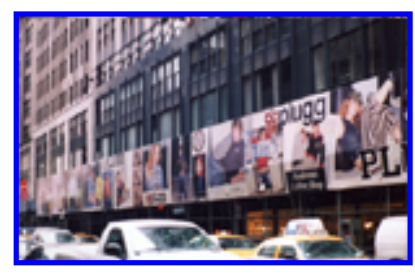


Figure 3. "[Outdoor] is the best way to reach people on the go...

even kids because they are being driven around to

all their after school activities..." - Outdoor Specialist

To reach an audience that is ever more mobile, outdoor needs to be everywhere. Arbitron Inc., a source for audience measurement, reports that commuting times for traveling to work oneway increased to an average of 25.5 minutes in 2000, up 13.8 percent compared to 1990 (Arbitron, 2003). The increased time provides commuters more opportunity to see outdoor media. Therefore, the industry touts the medium's availability to a mobile audience.

From its beginnings, outdoor advertising made sure it maximized exposure. The most desirable locations had the heaviest traffic and that is where the poster was placed on its own board (OAAA Website, 2003). This practice continues today with messages carefully placed to optimize the full visual spectrum. Advertisements can be found high up on tall buildings, at street level on telephone kiosks, below in subways, and everywhere in between.

Advertisers can enhance the visual impact by selecting locations depending on the target audience, message, strategy, and creative. For example, Guess by Marciano puts a provocative visual at eye level (Figure 4). The fashion advertisement functions like a mirror for people walking down the street. He or she can stand next to it and project his or her self in the grunge look to try it on-how does it feel, as a friend or as one's self? It is very common in real estate to say location, location, location — and it is just as relevant for outdoor.

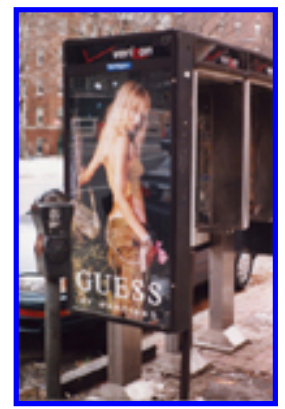

Figure 4. "[Outdoor] is in your face...no matter where you go, you can't get away from it... It's there, on taxis, highways, fliers, grocery store floors, coupons, telephones..." - Outdoor Production Specialist

In a marketplace like television or magazines, where mass media audiences are becoming fragmented, marketers are having a tougher time finding eyeballs. Advertising space is now so valuable that any surface that can carry a message to the public is considered a viable media option-including fruit, gasoline pumps, and bathroom walls. The Economist (2000, May 13) suggests outdoor may be the last true mass medium —an advertising vehicle that reaches everyone. Gutterman (2000, October) in American Demographics explains: "Outdoor advertising has always been considered the ultimate mass medium, reaching everyone" (p. 1).

Outdoor's sheer physical size makes it powerful. Traditionally, outdoor advertisements were painted on sides of buildings in the city, or on barns in the country. While still large, today's outdoor advertisements are not as easily defined.

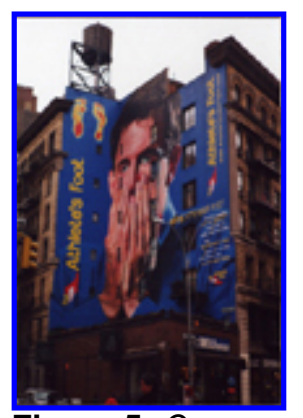

Figure 5. One reason for employing outdoor -

"You can't get much bigger." - Creative Director 
The picture is realistic in style-considering that the man's head is six stories high. Production qualities are complex. Not only is the image on an inside corner and visible in two directions, it is also asymmetrical and incorporates various rooflines and punctures for multiple size windows. The Athlete's Foot name and logo are clearly visible at least once in each direction. Nine lines of copy in different colors and lettering styles are part of the layout. A promotion specific website address is also provided.

Today's promotional campaigns are for quick consumption and immediate obsolescence. They emphasize change. With few exceptions, the time and money required to hand paint outdoor has become cost prohibitive. New technologies in printing and materials cater to advertisings challenges. Since about 1991 or1992, visuals are now most commonly printed on a vinyl material that is hung on buildings and posts. The net-like construction allows huge images to be relatively lightweight and fully cover building façades. The method continues the illusion of the traditional painted outdoor advertisement while increasing speed of production and imitating other print media.

Advertisements for BMWFILMS.COM and The Corcoran Group (Figures 6 and 7) are two examples of this new technique. The viewer can hardly notice the vinyl, and the advertisements appear as if they were the skin of the building-complete with windows. Both images are realistic, probably printed from digital technology, and very large - the standing man dressed in a black suit is eleven stories high, while a woman real estate agent's profile is more than four floors high.
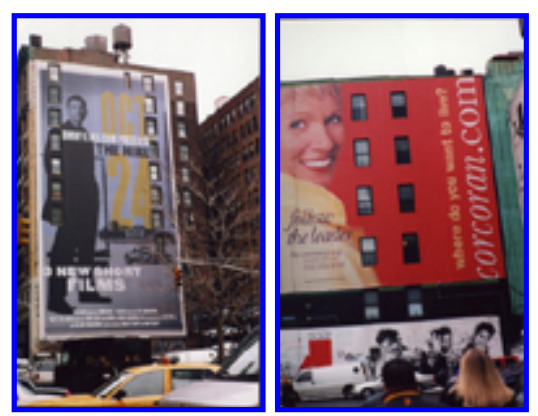

Figures 6 and 7. A new "mesh" is used not only on buildings but also on conventional billboards - large bulletins and smaller posters.

Billboards that we see on highways are now typically wooden boards "wrapped in a giant condom." The mesh material can be printed on, withstand all types of weather, and is easily transportable to allow boards to be rotated to several locations to capture different traffic and more audiences. - Production Specialist

Images that were once science fiction are now real—the girl next door is twenty-five feet tall! Take for example the Louis Vuitton advertisement showing a beautiful, emaciated woman struggling through a clutch of handbags like a lioness seeking her pray-a juicy Louis Vuitton bag (Figure 8). Although she is properly clad and suitably shod, her figure is stretched with elongated body parts-arms, legs and torso-with skin tanned in gold. In contrast, the prize handbags look completely normal. The visuals come together like a surrealist paintingcreating an idealizing, dream-like experience.

The image brings forth several possible interpretations, all of which would be considered a cultural negative, but an advertiser's positive, because it attracts attention and ultimately builds awareness and hopefully sales. The model is not flattering to women, but it is a picture that sells to women. Strategically placed, the advertisement can be fully savored.

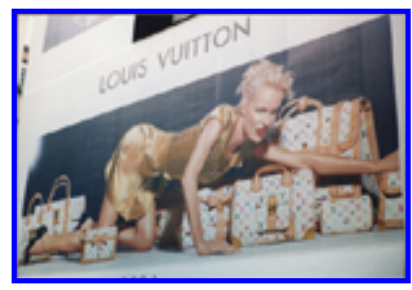


Figure 8. Reasons for using women in outdoor advertisements "Women are generic, culturally...Everyone can relate to a nice looking women - men and women." - Creative Director

How is this advertisement different from those with men? For example, the "khakisreshaped" advertisement for Gap shows a giant man (Figure 9). Unlike the woman, he is not posed; but like a Muybridge photo, is suspended in a split second depiction. He is obviously a man caught in action and nothing more, while the lioness woman in the Luis Vuitton visual is specifically posed.

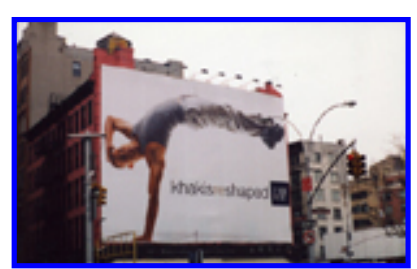

Figure 9. Strategies for creative - "You need to be fun and risky and smart... you can't ignore the scene, but play into it... Sometimes you have to one-up what's already out there." - Creative Director

Because of its potential impact, outdoor is used as a branding tool for creating an emotional bond between target consumers and products. According to marketing consultant Maskulka (1999), Proctor \& Gamble, one of the largest advertisers, uses outdoor as a "giant creative canvas" by which to change the image of the brand" (p. 3). Creative professionals generally agree that the use of outdoor "is a great branding experience." The dreamlike imageswhether they are of crawling around Louis Vuitton bags or acquiring Olympic gymnastic ability through the purchase of Gap clothes-involve the viewer at a mental and emotional level. This gestalt creates a relationship, an important goal of branding.

\section{Intimacy Attracts Attention}

Intimacy is the ultimate of relationships. Male and female nudity sells. In the Jockey billboard (Figure 10), the classic " $Y$ " front attracts attention because it's the next best thing to being naked. Here, words emphasize the visual, as if the visual were not enough. The viewer can complete the narrative with his or her imagination about the man and woman lounging in bed with a cup of coffee and newspaper. The more involved the viewer, the better the branding effect.

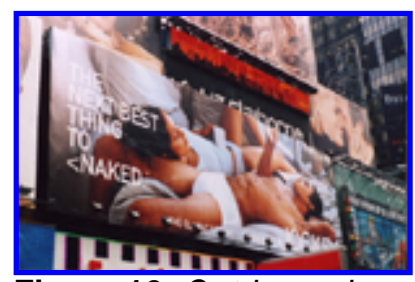

Figure 10. Outdoor ads and images "have a great branding presence... and [some campaigns] couldn't have been done with other media, like radio, and simply impossible with TV." - Creative Director

Similarly, the Victoria's Secret poster displayed in a store window shows a woman in a fitted tank top and panties (Figure 11). The model's fingers tug at her shirt in a way that emphasizes her crotch area. Her hands could be positioned anywhere, but through her body positioning, her slightly tilted head, and her expression, the image is a casual, if intimate, sexually charged pose. 


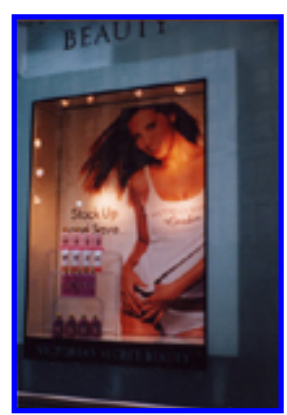

Figure 11. Women are about "culture, along with sex, death, taxes, drinking, and having fun." - Creative Director

Granted, the last two examples are for undergarment manufacturers and messages may need to be explicit. But not always so. Playtex, also in the business of intimate wear, uses a relatively modest visual (Figure 12). The blond, blue-eyed model looks directly at the camera while her pale skin seems to disappear into the white background-effectively highlighting the black product without implying intimacy.

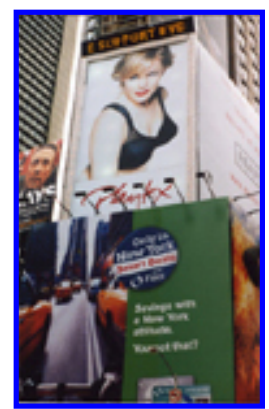

Figure 12. "[Outdoor] can't be too complicated, visually." - Creative Director

Visuals are often sexually suggestive in other ways. In Figure 13, the logo could be put anywhere, but it is placed by the woman's crotch. This is not incidental-it is consciously placed there by an art director who thought-angle in bold, hot colors. Is it an oversight that the colors of the logo are not repeated anywhere else in the composition?

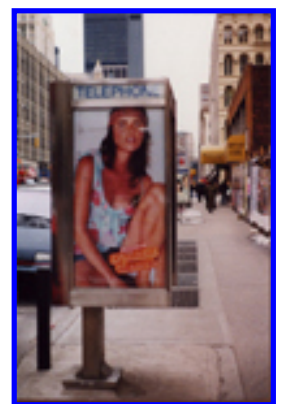

Figure 13. Outdoor has to "...create something that's visually arresting." - Creative Director

In a trio of stacked billboards, it is the figures that attract attention (Figure 14). At the top, a well-to-do, young, country club, Liz Claiborne woman with suitably appropriate jacket and purse, looks outside the composition, but not at the viewer. She is confidently blond and smiles naturally. Now consider the middle image. In American culture, the tongue is not an approved object of public display, in fact, it is deemed offensive. So how does a company like Swatch attract attention? Much like the famous Rolling Stone's album cover, a blazing red heart-shaped tongue is featured. But in this instance it belongs to a goofy-eyed woman whose big red extension is being assaulted by a long-pointed, thin, red strap of a Swatch watch. In contrast, on the billboard below, a male windsurfer rides a red, banana-shaped board. The man is physically active, participating in leisure interests. 


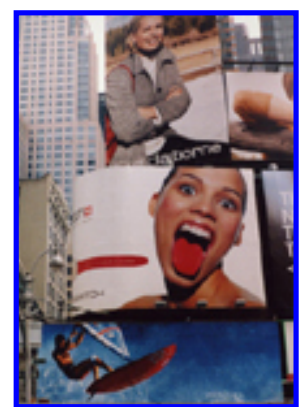

Figure 14. When asked why women should be used in outdoor boards, one creative director suggested, "to create an impression."

Simple Is Better

Creative considerations are often subjective, however, there is agreement that outdoor needs to be "simple." Not only is it necessary for potential customers traveling fast by car, taxi, train, or bus, to get the image, but it also may be effective because viewers are tantalized to work harder to discover and create the intended meaning. The process begs for an active and involved audience. The more a consumer contributes emotional and personal attributes to a brand, the more he or she assures him or herself of an associated mental image of the brand. The right mental concept can be highly influential.

The apparent formula, less is more, includes figures, often in an environment, with only a logo/ brand name completing the dimension. H\&M uses a man clad in clothes that are no different than those seen on the streets - tank top and khaki cargo shorts (Figure 15). The apparel is highlighted by a figure with outstretched arms standing on a ladder in front of a freshly painted mural. Through a relatively elaborate composition for a low-end sale, "Tank top $\$ 9$," the visual creates a feeling or image, an important part of branding.

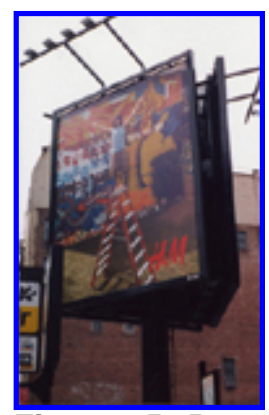

Figure 15. Parameters for outdoor design - "

The rule is five to seven words" and

"less is more... ten words or less." - Creative Directors

Target, lauded for its fresh and effective branding efforts, reduces the advertising message to its essence. In Figure 16, Target's already recognizable logo is used as the basis for guitar playing figures. The red and white color scheme immediately catches our eye and reminds us of the brand. Another reminder is that men are more active-like the painter on the ladder, the musicians are male.

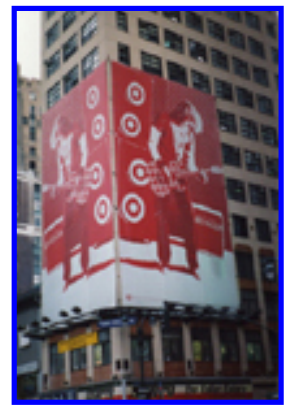

Figure 16. Outdoor is best to "build awareness" or "as a reminder" - Creative Director 
Although simplicity is good, when is it too simple? Do people, especially women, become mere props that are interchangeable? Another H\&M advertisement shows a woman in a top and jeans with copy that reads "Jeans $\$ 39$ " (Figure 17). She is shown from the back—no face. This woman is not allowed an identity. Perhaps it is not important - a woman can be replaced by any other. It is only about the jeans. Or is it? Does it tell us that women are only about butts, legs, and possibly backs?

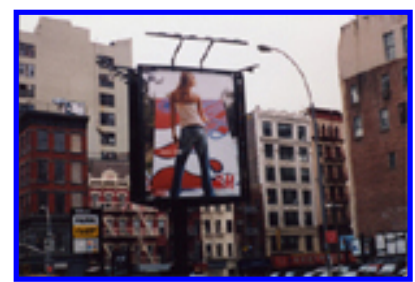

Figure 17. "Most people are just interchangeable." - Creative Director

As women appear more like props than people they can easily become statue-like figures. The visual for Dior J'adore (Figure 18) presents a woman from the chest up, the rest of her body cut off by a sea of gold. Her skin and hair seem to be gold-leafed. Her head, neck, face, and chest elongated while her arm is an enormous triangle that ends in one hand reaching towards a drop-like bottle. Her other hand is a freakishly shriveled claw jutting from her breast. Is she wading chest deep in a placid sea of liquid gold, slowly pushing the bottle ahead of her, or a museum piece-a sculpture of gold?

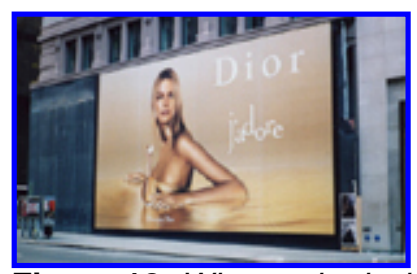

Figure 18. When asked why women should be used in outdoor advertisements, one creative director suggested for a "A quick read," while an outdoor specialist reflected, "You have to think of society, everyone will go to a good looking woman."

The Steve Madden image takes the human figure to inhuman proportions by exaggerating body parts (Figure 19). In this simple advertisement, the woman's head is very large, her torso petite, her legs long, and her boots specific. Is this her body? Yikes! Or maybe the camera has played a clever if not mean trick? Or is it all Photoshop? Have they been interchanged? Is it acceptable to cut and paste pieces of people? Or for that matter your own body? Today, pieces are easily bought and changed. Does this mean that society doesn't accept men or women for their natural selves?

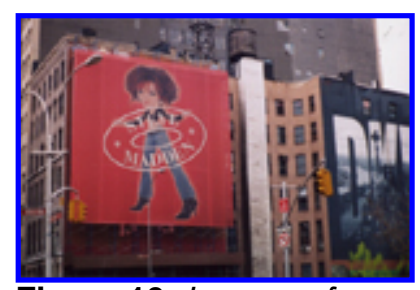

Figure 19. Images of women can "connect with people... broad enough for everyone... for kids, to the truck driver.

They convey a message to everybody." - Creative Director

\section{Stereotypes}

Not surprising, gender stereotypes exist. Broadly speaking, men are physically active and employed in productive careers, while a woman's job is to look seductive and be pretty. Some 
examples of stereotyping have already been noted. Now consider advertisements by the United States Postal Service, a branch of the Federal Government, in Figures 20 and 21 . Both genders in the visuals receive mail, in this case to support careers. However, the contents of the packages are quite different-the man gets sheet music, to enhance his intellectual spirit, while the woman gets a princess dress, to enhance her appearance.

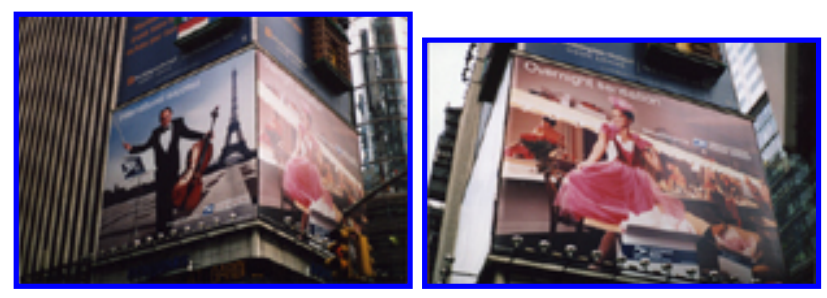

Figures 20 and 21. Women are symbols of "basic human truth, something everyone can relate to, they're about culture." - Creative Director

Some advertisers, such as the overworked businessman depicted by Discovery (Figure 22), support society's assumption that only men are interested in white-collar professions. What's startling about this visual is that it shows the man's back along with a cluttered desk. Not a very positive image. But another reading is that he is busy because he's successful. The text, "The electronic discovery solution created for attorneys, by attorneys" suggests that this man is an attorney, albeit, an old fashioned one, who is, as the headline offers, working to "Discover a better way." Unlike the woman noted in the H\&M Jeans advertisement (Figure 17) with her back to the viewer, this man has an identity-he's a lawyer. Furthermore, codes of age-a bald spot and suspenders-illustrate that men are allowed to grow old in their careers, unlike women in their jobs. The BT communications provider advertisement (Figure 23) also shows a businessman-a positive one of a young man, dressed in a slick business suit, white shirt and tie, rushing along with his briefcase.

Other stereotypical portrayals are relevant to gender. Men are often depicted in tough guises, boxed into narrow masculine roles that require them to be rough and mean. "Birdman" (also in Figure 23) illustrates this attitude. Our culture doesn't allow men to be sensitive or to show emotion.

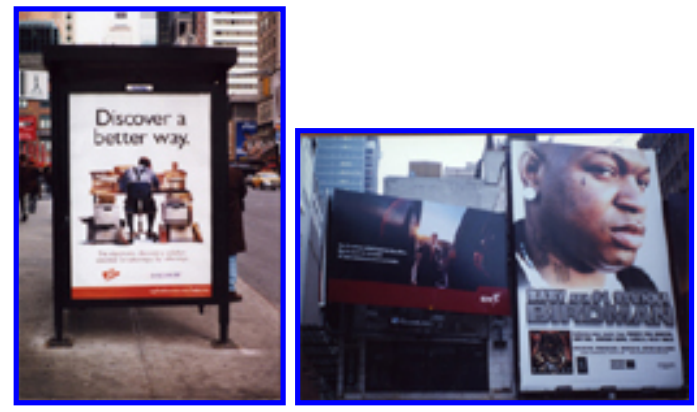

Figures 22 and 23. "[Women] should not be about just cleavage, but images need to resonate with the target audience, the idea needs to be hooked into something more with buzz. [Therefore, ads] could be more intellectual." - Creative Director

Often in visuals women are seen isolated. The dread-locked woman in the Lady Enyce image (Figure 24) stands alone in front of a wooded wall, jacket held together only by her hands thrust in its pockets, almost like a runaway. The letter style is desperately unspecific.

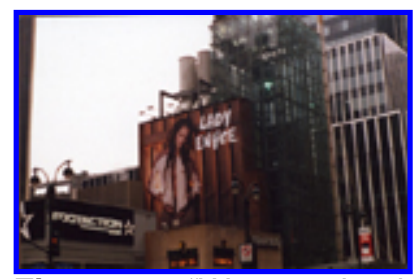

Figure 24. "Women should be used for their beauty." - Production Specialist 
If the male stereotype exists at all, then it is alive and well in Calvin Klein advertisements (Figures 25 and 26). The image-two-thirds surfer hunk, one-third jeans-is all about the idealized, idolized, male upper body. Is this a male beauty desired only for his pecs and pants? Does he have any other attributes? Cryptic thoughts? The pumped-up chest and biceps are seen on billboards around Manhattan and in slightly different configurations at many a local gym-increased frequency builds awareness.

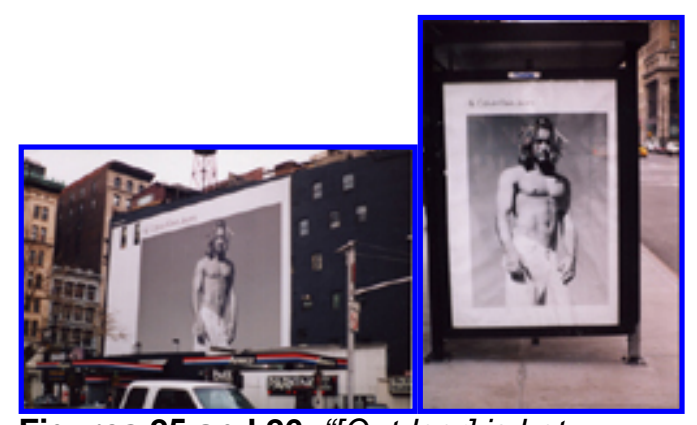

Figures 25 and 26. "[Outdoor] is hot...

it's the last true mass medium." - Production Specialist

\section{Survival Together}

After all, the genders must coexist and interact in society. So how are they depicted getting along together in advertisements? Two outdoor boards give us an idea of how they survive. The Dolce \& Gabbana visual presents a family portrait (Figure 27). Their 1960s British Invasion style, including long hair for men, straggly hair for women, mod floral-like prints, and peasant blouses, create a family unit. Everyone is in high retro, a free spirit look that is contrived for today's market.

For the young, hot, and nubile, Tommy Jeans are essential when "hanging" (Figure 28). Nine young men and women do the jungle-all-around thing, dressed in everyday urban, street, jungle fashion-modestly long pants over fashionably exposed undergarments with open shirt and shell medallion necklaces for men, cut-offs and low slung hip-huggers with pronounced bikini tops for women. They are all survivors, just as seen on television. Like a wilderness theme park, a hideaway that is entirely accessible by plane, these folks are expressing their consumer individualities.

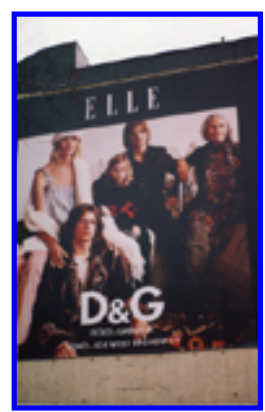

Figure 27. "We're pretty much in touch... you have to be a cultural junkie. It's not just media, but it's radio, it's art, fashion..."

- Advertising Practitioner (Soar, 2000, p. 428).

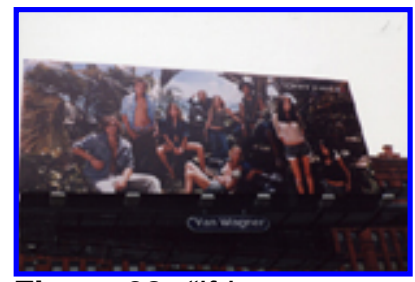

Figure 28. "If I see some technique done in a movie, I will always apply that to an ad." - Creative Director

\section{Conclusions}


Most Americans have become so accustomed to advertisements, that without them, they would be lost. People spend as much time, if not more, gazing at visuals at Times Square as they do shopping, eating, browsing, and carousing. What, then, is the real attraction?

Advertising sells anything and everything. If you want something, there is someone not only willing to sell it to you, but they are advertising so you know where to look. Advertising, especially using gender images, is a sensitive barometer of the tastes, concerns, priorities, mores, and attitudes of culture.

Advertisers are realists. They can't afford their message to be too idealistic. They have to present the best of what they know their audience wants. They need to be cautious enough not to overshoot and bold enough not to hit below the mark.

People in advertisements communicate the message. They socialize it. They give us a role model for what is right, beautiful, and normal at any given moment. The advertiser is both the shaper and the shaped. They give us gender specific advertisements to tell us what it is like to be a man or a woman.

Because they are economically successful, democratic, and visually non-restrictive, outdoor advertisements are ubiquitous. Geared for a mobile audience, the advertiser's outdoor messages blanket the visual spectrum. Visuals capitalize on location, location, location-to intersect with potential customers-whether it's at sidewalk level or attached high to a building. Big is better. Bigness offers powerful imagery-only in the recent past has it been possible to show an enormous real photo of a face or other body part. Today, images are real, neighborly, and enticing. Like the giant movie screen of long ago, billboarded brand messages dynamically communicate. Images are powerful influences to reinforce certain values and not others.

Composition, poses, design, and size-the visual aesthetics of outdoor advertisements-help create cultural values and highlight gender roles. Women, in body and dress, as seen in Louis Vuitton and Dior J'adore advertisements, are idealized. Compared to men, they are inactive, posed, and commonly depicted with no identity, and in isolation, as in images for Lady Enyce and H\&M Jeans. In general, women are props. Images of women are good for selling lifestyle and fashion. Women are consciously selected to sell certain commodities that are in someway associated with sexiness. To satisfy this consumer desire, women are depersonalized through idealization, stately clothes, and cryptic thoughts. In a word, they are stereotyped.

Men are action figures-active and realistic. Different parts perform different functions. Men are depicted in careers. Men are in pursuit of advancement and opportunities. They are shown playing musical instruments and windsurfing. They are also shown in professions, from stereotypical hunks to rushing businessmen to overweight and overworked attorneys. Sometimes men are shown outside traditional role definitions such as the idealized male model in the Calvin Klein advertisements. Here the male is a bridge between fantasy and reality. This idealizing of the unfettered free spirit that defines our consumer culture and drives democratic outdoor advertisement is very limited.

Overall gender roles rule and remain tethered to consumerism. These roles are deeply rooted in our society, while the free spirit is always an ideal just beyond actual reach. In outdoor advertisements, this setting spills into the interaction of genders and embraces the fictional nonconformity that generates sales.

\section{Notes}

${ }^{1}$ The CinemaScope screen was developed in the late 1920 s and premiered to the public in the 1953 film, The Robe (Widescreen Museum Website, 2005).

${ }^{2}$ Systematically, walking block-to-block, I covered the most heavily traveled areas of 
Manhatten: From 59th to Pearl Street (south of Canal), north and south, and from Lexington to $8^{\text {th }}$ Avenue, east and west. Shopping, wholesaling, warehousing, commercial, and residential are represented in neighborhoods that include Midtown, Times Square, Chelsea, Greenwich Village, Little Italy, Chinatown, and Washington Square. Images were collected from February 27 to March 2, 2003.

${ }^{3}$ Interviews were held between February 24 and March 19, 2003 with durations between 40 minutes to 1-1/2 hours for a total of over eight hours. Discussions with informants took place at various locations-offices and coffee shops around a northeastern university and in New York City. With their permission, notes were taken and elaborated into text immediately after each session.

${ }^{4}$ Following examples of other studies with production professional interviews (Heider, 2000), I constructed a list of eight broad questions focusing on outdoor advertising and gender that provided parameters for discussions.

${ }^{5}$ Jared Bell's office in New York is credited with the first large (over 50 square feet) outdoor poster (OAAA Website, 2003).

\section{References}

Arbitron, Inc. (2003). "Outdoor Advertisers Have More Viewers," January 23. Retrieved March 27, 2003, from <http://www.aooo.org>

Bordo, S. (1993). "Anglo-American Feminism, 'Women's Liberation,' and the Politics of the Body." In L. McDowell, \& J. P. Sharp (Eds.), Space, Gender, Knowledge: Feminist Readings, 232-236. London: Arnold.

Butler, J. (1997). Excitable Speech: The Politics of the Performative. New York: Routledge.

Buttle, F. (1989). "Sex-Role Stereotyping in Advertising: Social and Public Policy Issues." The Quarterly Review of Marketing, Summer, 9-14.

D'Andrade, R. (2001). The Development of Cognitive Anthropology. NY: Cambridge University Press.

The Economist. (2000). "The Smartest Bus Shelter Ever." The Economist, May 13, 62-63. Retrieved March 5, 2003, from FirstSearch database.

Gutterman, J. (2001). "Outdoor Interactive." American Demographics, August, 32-34.

Retrieved March 5, 2003, from FirstSearch database.

Heider, D. (2000). White News: Why Local News Programs Don't Cover People of Color. Mahwah, NJ: Lawrence Erlbaum Associates, Publishers.

Lakoff, G., \& Johnson, M. (1980). Metaphors We Live By. Chicago: The University of Chicago Press.

Maskulka, J. M. (1999). "Outdoor Advertising: The Brand Communication Medium." Retrieved March 6, 2003, from <http://www.aooo.org>

Pillar, I. (2001). "Identity Constructions in Multilingual Advertising." Language in Society, 30, 153-186.

Soar, M. (2000). "Encoding Advertisements: Ideology and Meaning in Advertising Production." Mass Communication \& Society, 3(4), 415-437. 
Tocker, P. (1969). "Standardized Outdoor Advertising: History, Economics, and SelfRegulation." In J. W. Houck, (Ed.), Outdoor Advertising: History and Regulation, 11-56. Notre Dame, IN: University of Notre Dame Press.

Williams, R. (1980). "Advertising: The Magic System." In R. Williams Problems in Materialism and Culture: Selected Essays, 170-195. London: Verso.

\section{Pamela Morris}

Pamela Morris is an Assistant Professor at the College of Journalism and Mass Communications at the University of Nebraska-Lincoln. She has over 18 years of account management experience in the advertising industry and has traveled extensively in pursuit of her research interests in advertising, mass media, world culture and visual and aural literacy, aspects of which she teaches. Morris received her doctorate in 2004 from the S.I. Newhouse School of Public Communications at Syracuse University.

Copyright $\odot 2005$ by The Advertising Educational Foundation, Inc. All rights reserved.

\begin{tabular}{|l|l|l|} 
MUSE & SEARCH & CONTENTS \\
\hline
\end{tabular}


Table 1. Summary of outdoor advertising with people in New York City by product category and vehicle type.

\begin{tabular}{|l|l|l|l|}
\hline \multicolumn{1}{|c|}{ Product/Service Category } & Billboards* & Transit** & $\begin{array}{c}\text { Street } \\
\text { Furniture }\end{array}$ \\
\hline Fashion & 36 & 1 & 27 \\
\hline Occupations & 2 & 1 & 2 \\
\hline Telephone Services & - & - & 4 \\
\hline Beverages & 4 & 2 & - \\
\hline $\begin{array}{l}\text { Finance, Insurance, Delivery, } \\
\text { Office Communication Systems }\end{array}$ & 10 & - & - \\
\hline $\begin{array}{l}\text { Hard Goods - Autos, Sound } \\
\text { Equipment }\end{array}$ & 3 & - & - \\
\hline Print Publication/Imaging & 2 & 1 & - \\
\hline Entertainment & 25 & 3 & 2 \\
\hline Other - Adult Shops, Cigarettes & - & - & 8 \\
\hline Public Service Announcements & 1 & - & - \\
\hline Totals (N = 134) & $\mathbf{8 3 ( 6 2 \% )}$ & $\mathbf{8 ( 6 \% )}$ & $\mathbf{4 3 ( 3 2 \% )}$ \\
\hline
\end{tabular}

Categories based on definitions by the Outdoor Advertising Association of America, Inc., although the study was limited in scope to include the following:

*Billboards include Bulletins, 8 and 30-Sheet and Square Posters, including those wrapped, Spectaculars and Wall Murals, including those on mesh and building and sidewalk scaffoldings.

**Transit includes Bus Posters and Subways and Rapid Transit Rail System Signage. *** Street Furniture includes Information and Telephone Kiosks, Pedestrian Panels, InStore and On-Premise Displays and Urban Panels. 
Table 2. Summary of outdoor advertising with people in New York City by product category and gender.

\begin{tabular}{|l|l|l|l|}
\hline \multicolumn{1}{|c|}{ Product/Service Category } & \multicolumn{1}{|c|}{ Men } & \multicolumn{1}{c|}{ Women } & \multicolumn{1}{c|}{$\begin{array}{l}\text { Women } \\
\text { Women }\end{array}$} \\
\hline Fashion & 9 & 40 & 13 \\
\hline Occupations & 3 & 2 & - \\
\hline Telephone Services & - & 3 & 1 \\
\hline Beverages & 3 & 1 & 2 \\
\hline $\begin{array}{l}\text { Finance, Insurance, Delivery, } \\
\text { Office Communication Systems }\end{array}$ & 6 & 2 & 1 \\
\hline $\begin{array}{l}\text { Hard Goods - Autos, Sound } \\
\text { Equipment }\end{array}$ & - & 1 & $2^{\star}$ \\
\hline Print Publication/Imaging & - & 2 & 1 \\
\hline Entertainment & 11 & 6 & 13 \\
\hline Other - Adult Shops, Cigarettes & - & 8 & - \\
\hline Public Service Announcements & - & - & 1 \\
\hline Totals** (N = 131) & $\mathbf{3 2} \mathbf{( 2 4 \% )}$ & $\mathbf{6 5} \mathbf{( 5 0 \% )}$ & $\mathbf{3 4} \mathbf{( 2 6 \% )}$ \\
\hline
\end{tabular}

*Includes board with an unidentifiable gender.

**Figures do not include 3 outdoor images with children only.

Table 3. Summary of outdoor advertising with people in New York City by fashion and non-fashion categories and gender.

\begin{tabular}{|l|l|l|l|l|}
\hline \multicolumn{1}{|c|}{ Product/Service Category } & \multicolumn{1}{c|}{ Men } & \multicolumn{1}{c|}{ Women } & $\begin{array}{c}\text { Men \& } \\
\text { Women }\end{array}$ & \multicolumn{1}{c|}{ Total } \\
\hline Fashion & 9 & 40 & 13 & $62(47 \%)$ \\
\hline Non-Fashion & 23 & 25 & $21^{\star}$ & $69(53 \%)$ \\
\hline Totals $^{\star *} \mathbf{( N ~ = ~ 1 3 1 ) ~}$ & $\mathbf{3 2 ( 2 4 \% )}$ & $\mathbf{6 5 ( 5 0 \% )}$ & $\mathbf{3 4 ( \mathbf { 2 6 \% ) }}$ & $\mathbf{1 3 1 ( \mathbf { 1 0 0 } \% )}$ \\
\hline
\end{tabular}

*Includes board with an unidentifiable gender.

${ }^{* *}$ Figures do not include 3 outdoor images with children only. 